\title{
Occult elbow dislocation: A rare cause of upper limb arterial insufficiency
}

\author{
IA McMurtry, TJ Bhullar
}

\begin{abstract}
We present a case of vascular injury resulting from occult dislocation of the elbow joint. At last review 46 cases of brachial artery injury with concomitant dislocation have been reported (10), all in small series and case reports. In all the dislocation was clinically or radiologically evident.
\end{abstract}

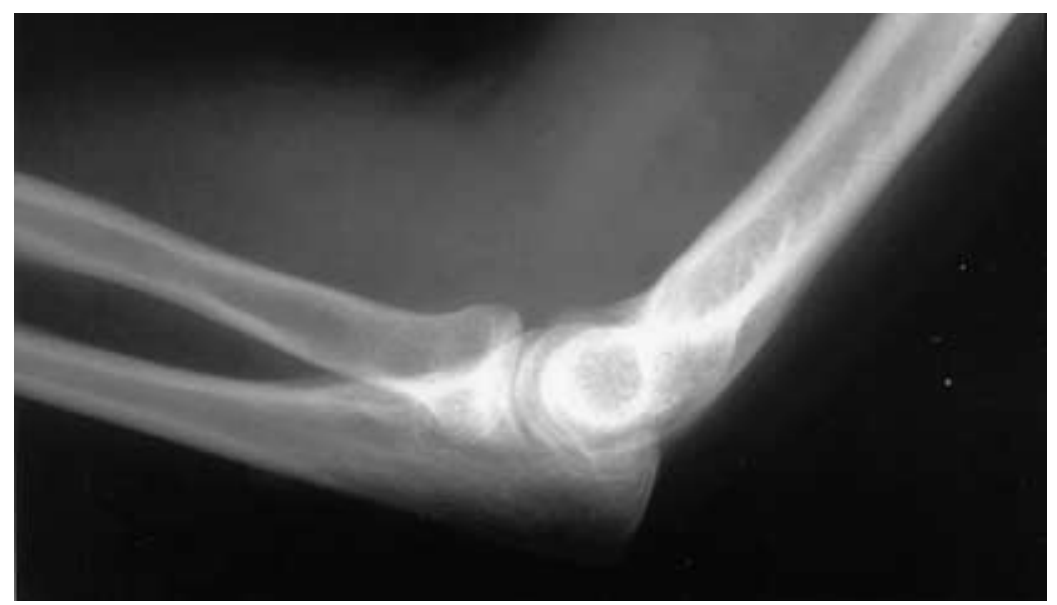

Fig $1 a$.

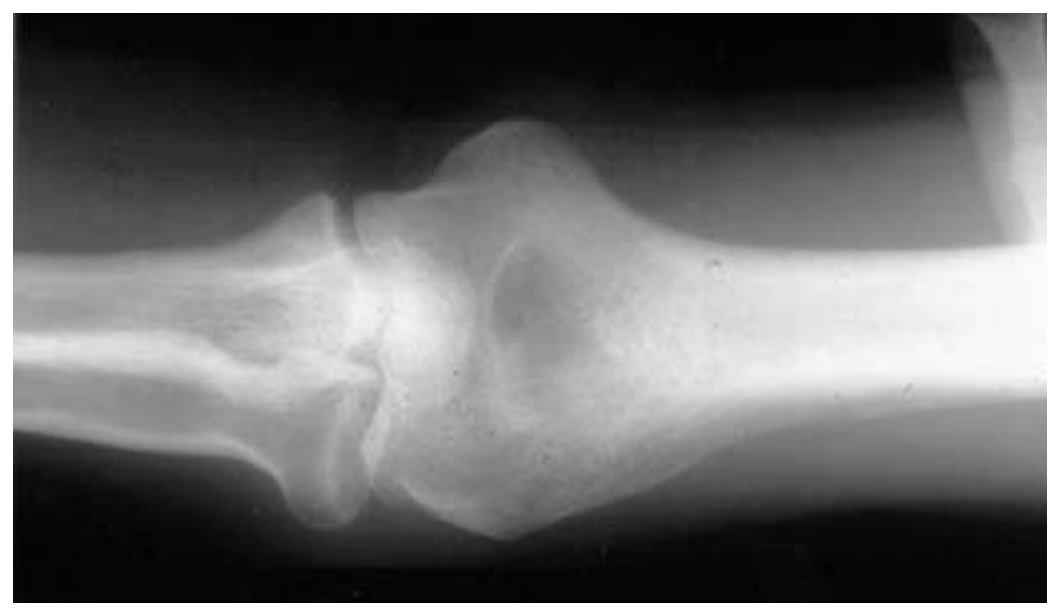

Fig $1 b$.

Maj IA McMurtry

FRCS RAMC

Orthopaedic Specialist

Registrar

Wg Cmdr TJ Bhullar FRCS(Orth) RAF

Orthopaedic Consultant

Department of

Orthopaedics, MDHU

Peterborough

\section{Case History}

A 32 year old woman presented acutely complaining of numbness and tingling in her left hand, with associated swelling of the forearm, following a fall. On examination the limb was swollen with bruising medially with radial and ulnar pulses impalpable at the wrist. Sensation was altered in all fingers. The elbow joint moved freely through an arc of $40^{\circ}-85^{\circ}$. AP and Lateral radiographs of the elbow were normal (Figs at the elbow. The hand was dusky and cool
$1 \mathrm{a}$ and $1 \mathrm{~b}$ ) and flexor compartment pressures were within normal limits.

In view of a suspected arterial injury surgical exploration was undertaken. On examination under anaesthesia the elbow joint was found to be unstable and dislocatable posteriorly. A diagnosis of traumatic dislocation with concomitant arterial injury was made. On exposure she was found to have a complete transection of the brachial artery. The median nerve was the only intact structure anterior to the joint, although contused, with complete disruption of capsule, biceps tendon, and brachioradialis. Arterial re-anastomosis was achieved with a reverse saphenous vein graft, the joint not requiring any reconstruction as it was stable in flexion. Formal forearm fasciotomies were performed.

Post-operatively the arm was splinted at $70^{\circ}$ of flexion in a well padded backslab for 3 weeks. Active self mobilisation then followed. At final review five months post injury the elbow joint was stable, with an arc of movement $0-130^{\circ}$.

\section{Discussion}

The incidence of vascular injury in association with dislocation is low. It is more commonly associated with supracondylar fractures of the humerus (7) with an incidence as high as $13 \%$. (3) In the largest series of 110 dislocations Linscheid reported only 6 cases with an arterial injury (7).

Diagnosis can be difficult due to the excellent collateral circulation of the elbow, as illustrated by Louis (8). Another pitfall is the presence of intraluminal pathology. Thus opinion on the correct method of diagnosis varies. Pulses may still be present or detectable on doppler despite complete transection of the brachial artery (11). Contusions, intimal disruptions and occlusive thrombus cannot be diagnosed at surgical exploration. However Shuck (12) and Moheb (10) recommend resection of a "bruised" segment of artery as their series found this consistent with luminal pathology and occlusion. Arteriography, standard or digital, should help to diagnose these lesions, but have their own inherent complications and delays. (4) Each of these modalities has it's merits, but the eventual treatment algorithm will be dictated by local facilities and expertise. 
Our operative treatment follows standard guidelines with reverse vein grafting and fasciotomy. Arterial ligation has been advocated (1), but despite the collateral supply, carries an eventual amputation rate of up to $33 \%$ (2). In addition it is associated with exercise claudication and cold intolerance (9). Joint reconstruction is not necessary as long term instability is not a consequence, and reconstruction has been shown to produce a worse functional outcome $(5,6)$.

Our case illustrates a rare cause of upper limb ischaemia. It emphasizes the need for thorough clinical examination of all systems in a traumatised limb despite no gross deformity. One should not be misled by "normal" radiographs as they show only the position of the bone or joint at the time the radiograph was taken. They convey nothing of the displacement at the time of injury. Good clinical acumen is essential for a good outcome.

\section{References}

1. Amsallem JL, Blankstein A, Bass A, and Horoszowski, H. Brachial artery injury. A complication of posterior elbow dislocation. Orthopaedic Review 1986, 15(6), 379-382.
2. Ashbell TS, Kleinert HE, Kutz JE. Vascular injuries about the elbow. Clin Orthop 1967: 50: 107-126.

3. Endean, ED, Neldenz HC, Schwarcz TH and Hyde GL. Reconstruction of arterial injury in elbow dislocation. F Vascular Surgery, 1992, 16: 3, 402-406.

4 Field JR, Lee L, McBurney RF. Complications of 1000 brachial arteriograms. F Neurosurg 1972; 36: 324-332.

5 Grimer RJ and Brooks S. Brachial artery damage accompanying closed posterior dislocation of the elbow. FB7S (Br) 1985. 67(3): 378-381.

6 Joseffson PO, Gents CF, Johnell O. Surgical v's non-surgical treatment of ligamentous injuries following dislocations of the elbow joint. Clin Orthop 1987; 214: 165.

7 Lindsceid, RL and Wheeler DK. Elbow dislocation. FAMA, 1965 194: 1171-1176.

8 Louis DS, Ricciardi JE, Spengler DM. Arterial injury as a complication of posterior elbow dislocation. FBFS 1972; 56(A): 1631-1636.

9 Mains DB, Freeark RJ. Report on compound dislocation of the elbow with entrapment of the brachial artery. Clin orhtop Rel Res 1975; 106: 180-5.

10 Moheb S, Moneim MD, Jeffery R, and Garst MD. Vascular injuries associated with elbow fractures and dislocations. International Angiography, 1995, 14(3): 307-312.

11 Perry MO, Thal ER, Shires GT. Management of arterial injuries. Ann Surg 1971; 173: 403.

12 Shuck JM, Omer GE, Lewis CE. Arterial obstruction due to intimal disruption in extremity fractures. F Trauma 1972; 12: 481-489. 